\title{
Community based, effective, low cost approach to the treatment of severe malnutrition in rural Jamaica
}

\author{
Maria T Bredow, Alan A Jackson
}

\begin{abstract}
Moderate and severe malnutrition are endemic in much of the developing world and in association with pockets of deprivation in the developed world. The cost in terms of individual and social development is high. The principles of effective management are clearly documented. A low cost, community based treatment programme for moderately and severely malnourished children under 3 years of age was established at a health centre in rural Jamaica. Children were followed up monthly and defaulters were rigorously recalled. Management consisted of carefully delivered dietary advice, antibiotics, anthelminthics, and vitamin supplements. All children improved and the response of 36 children, who were treated in the first year, showed an accelerated weight gain, with catch-up growth and the maintenance of length gain. There was a significant increase in the weight for age, at $1.9 \%$ per month over six months, which exceeds the rate reported with food supplementation programmes and nutrition rehabilitation centres.
\end{abstract}

(Arch Dis Child 1994; 71: 297-303)

Over the years the approach to the management of severely malnourished children has changed. The high mortality associated with high costs of hospital based treatment led to a period when outpatient management in nutrition rehabilitation centres, matched with preventive programmes, gained widespread support. ${ }^{1-4}$ One consequence of this was the perception that severe malnutrition was primarily caused by a simple shortage of food and that the provision of adequate amounts of food, in the form of supplementation programmes, would resolve the problem. Nutritional rehabilitation centres were developed for this purpose but had only limited success. $^{2-6}$ In part the indifferent outcome might have been because the provision of food alone failed to acknowledge a wider range of social and clinical problems. If all malnourished children are managed in a similar way, insufficient importance tends to be attached to the different approaches best suited to children with different degrees of severity. ${ }^{78}$ This shift of focus, and the implication that the problem had been solved as an issue of relevance to clinicians, resulted in a loss of interest in the development of more effective approaches to management. ${ }^{9}$ Thus, although in 1981 the
World Health Organisation (WHO) had published recommendations on The Treatment and Management of Severe Protein-energy Malnutrition, ${ }^{10}$ because the practical application of the advice failed to gain wide recognition it was never critically evaluated in the field.

In reviewing the situation, $C$ Schofield and A Ashworth (personal communication) have observed that mortality rates have changed little over the past 40 years (case fatality rates of at least 20 to $30 \%$ ), despite increase in knowledge and understanding. They conclude that the high mortality from severe malnutrition among children in most areas of the world can be directly attributed to faulty case management. As, in principle, the ability to manage a child with severe malnutrition is identical to the approach required for management in situations of famine, caused either by war or natural disasters, and also the management of depleted patients with nutritional support in the developed countries, there is a major cause for concern. The implications are that the inappropriate management is a reflection of a generation of doctors who have been trained with an incorrect understanding of the disease process and a wrong approach to management. ${ }^{10}$ All the evidence would suggest that the practices most often adopted are unnecessarily expensive as well as being ineffective (C Schofield, A Ashworth, personal communication). The lessons learnt over years of experience in the developing countries have not been incorporated as an essential part of medical knowledge and understanding in the developed countries. ${ }^{9}$

The most successful treatment programmes have been those in which regular follow up of malnourished children continues until full recovery has taken place and where good supervision of staff and patients is maintained. ${ }^{128}$ The establishment of such nutrition programmes linked to child health clinics under the guidance of well trained staff has been frequently recommended. ${ }^{1-5} 11$

The author (MTB), having been trained in the management of severe malnutrition in a specialised centre, sought to reproduce the experience in the setting of a normal rural clinic, with the objective of identifying how feasible it was to put into practice the recommendations in the WHO report. In this way it was hoped to obtain a clearer understanding of the practicality of the approach recommended, the level of experience and skill needed by staff to run the programme and hence the level of training and supervision that would be needed 

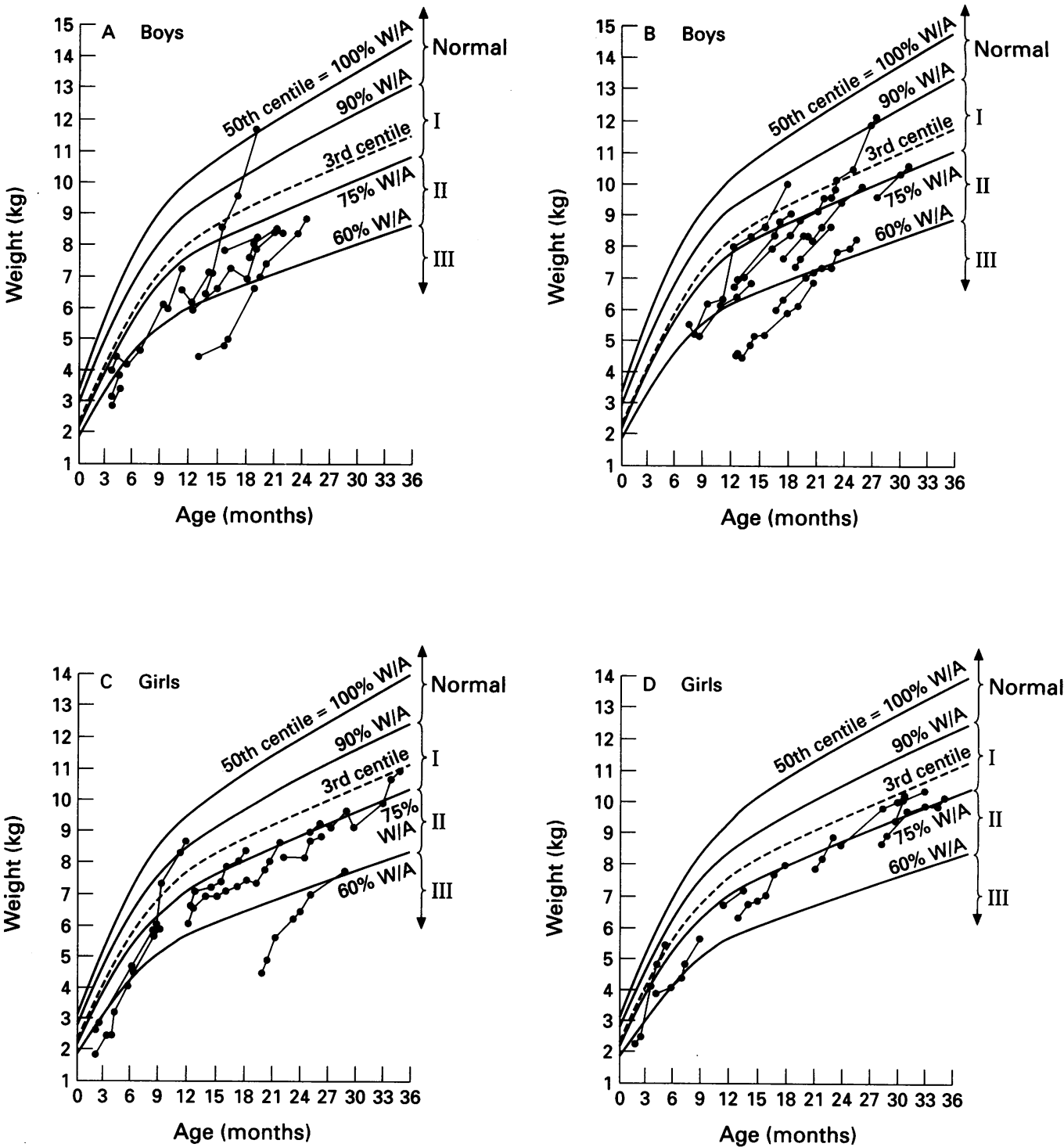

Individual weight charts for 20 boys ( $A$ and $B$ ) and 16 girls ( $C$ and $D$ ) with malnutrition for each time of review after registration. The centiles are derived from the NCHS reference data ${ }^{16}$ and the ranges for the Gomez classification (normal, I, II, and III) are shown (W/A =weight for age).

for effective widespread implementation of the recommendations. The setting of the study was a health clinic in rural central Jamaica during the late 1980 s.

\section{Methods}

\section{BACKGROUND}

Jamaica is a subtropical island with a population of 2.5 million. Malnutrition of some degree is a persistent problem in preschool children and, despite an overall fall in prevalence with time, the pattern of improvement is not even. There are localities in both urban and rural areas where the prevalence is either constant or increasing. Based on the classification of Gomez et al, ${ }^{12}$ the overall prevalence of moderate to severe malnutrition in children under 3 years of age has varied between $7 \%$ and $14 \%, 51314$ which is comparable with the prevalence in other countries in the Caribbean. ${ }^{15}$

The Balaclava Health Centre, in the parish of St Elizabeth, is a rural clinic in the sugar cane plantations of central Jamaica. The clinic served a population of over 14000 , of whom

just over 1000 were under 3 years of age. A doctor provided clinical cover through an outpatient clinic twice a week, but most of the clinical work was undertaken by nurses and community health aides (people selected from the community and trained with basic skills in identification of clinical problems and health promotion).

The progress of individual children was followed with a 'growth chart', with weight being used as the main criterion. The nutritional status of each child was formally identified according to the Gomez classification. ${ }^{12}$ In this classification the 50th centile for weight is taken as the reference standard, that is, $100 \%$ 'weight for age' (50th centile derived from National Center for Health Statistics (NCHS) data). ${ }^{16}$ The child's weight is determined as a percentage of the 50th centile with normal being $>90 \%$; Gomez grade I mild malnutrition, 75 to $89 \%$; Gomez grade II moderate malnutrition, 60 to $74 \%$; and Gomez grade III severe malnutrition, $<60 \%$. Children on the 3rd centile using NCHS data are approximately $80 \%$ weight for age, that is, within Gomez grade I (see figure). The annual report 
of the Department of Health showed that for St Elizabeth in 1986, of all the children under 3 years of age who were weighed at the Balaclava Health Centre, $66 \%$ were within the normal range of weight for age and there were 3\% with severe malnutrition (Gomez grade III), $9 \%$ with moderate malnutrition (Gomez grade II), and $22 \%$ with mild malnutrition (Gomez grade I).

\section{DEVELOPMENT OF THE PROGRAMME}

Before the introduction of the programme there was no defined plan in the clinic for the management of malnourished children. Large numbers attended the clinic and not all children were weighed on every visit, especially if they appeared relatively well, thus stunted children were sometimes overlooked. When a malnourished child was recognised, the approach to management was to give general nutritional advice and where appropriate to encourage breast feeding. Although medication provided at the clinic was free or at a nominal charge, the stocks were inadequate and the cost for purchasing at the private pharmacy were prohibitively expensive. There was no system for detecting those children who defaulted from follow up. In June 1987, a programme for managing children with malnutrition was established at the Balaclava Health Centre, and was based on the management received by malnourished children at a specialist nutrition unit (Tropical Metabolism Research Unit, University of the West Indies, Jamaica) that was broadly in line with the WHO guidelines. ${ }^{10}$

From the start of the programme emphasis was placed upon ensuring that all children under 3 years of age should be weighed on each visit to the clinic, and that the weight should be plotted on a growth chart that showed the Gomez grades. All children were weighed to the nearest $50 \mathrm{~g}$. Those in Gomez grades II and III and all children with nutritional oedema were considered malnourished and were entered into the treatment protocol. They were recorded in a special register and their notes were marked so that children making unscheduled visits could be easily identified. The register was checked on a regular basis and any child who had defaulted from an appointment was recalled by letter or telegram. The recumbent length of each malnourished child was measured to the nearest $0.5 \mathrm{~cm}$. Where possible the weight and height of the mother of each child was taken. Every malnourished child was seen by a doctor or nurse and a history and examination were undertaken to look for underlying disease. The child was then started on the treatment protocol which entailed specific dietary advice, medication, and regular follow up until the child reached 3 years of age.

\section{TREATMENT PROTOCOL}

(1) Dietary advice

Breast feeding was encouraged and an energy and protein enriched diet, based upon dried skimmed milk and either coconut oil or margarine was prescribed. All the ingredients were cheap and readily available in Jamaica and the mothers were expected to use their own resources to obtain them. The instructions on how to make up the feed were based upon two formulations: a maintenance formulation for the initial period of rehabilitation and a recovery formulation that would satisfy the needs for catch up growth. ${ }^{7}$

Maintenance formulation (from first visit): $140 \mathrm{ml} / \mathrm{kg} /$ day skimmed milk plus $30 \mathrm{~g}$ fat per litre of milk or $140 \mathrm{ml} / \mathrm{kg} /$ day full cream milk.

Recovery formulation (for catch up growth): $140 \mathrm{ml} / \mathrm{kg} /$ day skimmed milk plus $90 \mathrm{~g}$ fat per litre.

The mother was given simple but explicit instructions. For example, a $10 \mathrm{~kg}$ child was given 1.5 packs of milk powder (making 1.5 litres) and four to five soup spoons of margarine $(30 \mathrm{~g} / \mathrm{spoon})$ daily. This could be taken as a drink or made into porridge with cornmeal. Emphasis was placed on the importance of giving the child the special formulation as, in general, the family food would be of lower energy density. Therefore, if family food was to be offered, this should only be after each milk and fat meal, so as not to suppress the appetite of the child for the high energy formulation.

For the first week the maintenance formulation was to be given, as this provided sufficient energy (about $376 \mathrm{~kJ}(90 \mathrm{kcal}) / \mathrm{kg} /$ day) and protein to facilitate the return of normal metabolic function, without placing a metabolic stress on the system. ${ }^{7}$ During this time the child became accustomed to regular feeds, infections were treated, and vitamin supplements enabled the replenishment of specific deficiencies. An increase in appetite after about one week marked a general improvement in the child's condition. The formulation of higher energy $(627(150 \mathrm{kcal}) / \mathrm{kg} /$ day $)$ and protein density was introduced at this time to facilitate increased rates of weight gain. ${ }^{7} 17$

\section{(2) Medication}

The milk and fat feeds were considered to be the most important part of the management. Therefore, even if medications were not immediately available, the child was started on the dietary regimen. Medications were prescribed as follows:

Antibiotics - Silent infections may be the major reason for failure in response in any malnourished individual. ${ }^{18}$ In Gomez grade II any obvious infection was given appropriate treatment. In Gomez grade III and any child with oedema a broad spectrum antibiotic was given, even if there was no clinically apparent infection.

Anthelminthic - All children over 6 months of age were given mebendazole $100 \mathrm{mg}$ twice daily for three days. (Piperazine was considered to have a spectrum that was too narrow.)

Small bowel colonisation - A high index of suspicion existed for the presence of small bowel overgrowth and/or giardiasis and 
Table 1 Characterisation of 36 undernourished children (20 boys and 16 girls), according to the Gomez classification, at initial registration and at review after a period of management

\begin{tabular}{lcc}
\hline Gomez grade & $\begin{array}{l}\text { No of children } \\
\text { at registration }\end{array}$ & $\begin{array}{l}\text { No of children } \\
\text { at review }\end{array}$ \\
\hline Normal & 0 & 3 \\
I & $1^{\star}$ & 14 \\
II & 24 & 15 \\
III & 11 & 4 \\
Total & 36 & 36 \\
\hline
\end{tabular}

^This child had nutritional oedema.

therefore metronidazole $50 \mathrm{mg} / \mathrm{kg} /$ day was given electively for five days.

Micronutrients - All children were presumed to require supplemental vitamins and a multivitamin preparation and folic acid were given daily for one month.

Iron supplements - Excess iron can be damaging in malnutrition, but during catch up growth, reserves might become depleted. Therefore, iron ( $2 \mathrm{mg} / \mathrm{kg} /$ day) was given for one month once weight gain was established.

At the front of each child's notes a tally was maintained of which medications had been received. In this way any medication that was not immediately available, at the time when the child was registered, could be dispensed when it came into stock. In those children who remained in Gomez grade II or III malnutrition after six months, the course of medication was repeated, or in any child where the clinical need arose. All the children received a complete course of immunisations and all the mothers were given advice on contraception.

\section{(3) Follow up}

Children in Gomez grade II malnutrition were seen one week after the initial registration and then at monthly intervals if they were well. Children in Gomez grade III, those with nutritional oedema, and those who were clinically ill were seen at least weekly at first, then monthly once improvement had become established. Children who were severely ill and those who did not thrive on the protocol were referred to hospital.

When a child achieved Gomez grade I on the high energy feed, a normal mixed diet was introduced. The guardian was encouraged to continue mixing some fat into the child's food to prevent deterioration. The child continued to be monitored at intervals of one to two months until 3 years of age. If any child showed deterioration by dropping to Gomez grade II or III malnutrition the programme was recommenced. Beyond 3 years of age the children were seen according to clinical need only and defaulters were not sought specifically.

\section{Results}

The programme was reviewed at the end of the first year (June 1988). At that time there were 45 children on the malnutrition register: 28 boys and 17 girls. Children had entered the programme throughout the year and treatment periods ranged from less than one month to 12 months. Four children had presented with nutritional oedema and in each case the oedema had resolved within two weeks of starting the programme. Only one child had been referred to hospital; this was a boy aged 4 weeks who was Gomez grade II. He presented with fulminant meningitis and died in hospital two days later. At the time of the review nine children, including the child with meningitis, had only made one visit to the clinic and therefore were excluded from the analysis of the changes in weight and height. All nine children were Gomez grade II.

\section{(1) WEIGHT AND WEIGHT FOR AGE}

All 36 malnourished children (20 boys, 16 girls), who attended the clinic more than once, gained weight. The individual growth charts are shown in the figure and it is obvious that for the most part there was catch-up in weight. Table 1 shows the overall changes in the Gomez grade. On average, weight had increased by $2.03 \mathrm{~kg}$ over a period of 5.6 months. It is not easy to determine the relevance of these values, because it is normal for children to gain weight. If the change is expressed as weight for age, however, then none of the children deteriorated, three remained at the same weight for age, while 33 showed an improved weight for age, hence accelerated weight gain. The mean increase in weight for age of about $11 \%$ over 5.6 months was significant $(\mathrm{p}<0.01$, Student's $t$ test $)$ (table 2). There was no evidence that the enhanced rate of weight gain was slowing down as the 10 children who had been in the programme for over eight months were still improving over the last four months $(1.6 \%$ per month, $0.33 \mathrm{~kg} /$ month) compared with the first four months of their treatment $(1.3 \%$ per month, $0.30 \mathrm{~kg} /$ month).

Comparing the sexes, there was no significant differences in age of presentation, severity at presentation or response to treatment as determined by weight gain (table 2 ). However, if Gomez grades were compared, the children in Gomez grade III were much younger (mean 8.7 months) than those less severely malnourished in Gomez grade II (mean 16.3) months) (table 3 ). The severely malnourished children showed a mean increase in weight for age of $15.3 \%$, almost twice that of the moderately malnourished children $(8 \cdot 9 \%)$ over the

Table 2 Changes in the age, weight, and weight for age of 36 malnourished children (20 boys and 16 girls) between initial registration and review. Values are means (SD)

\begin{tabular}{|c|c|c|c|c|c|c|c|c|c|}
\hline & \multicolumn{3}{|c|}{ At registration } & \multicolumn{3}{|l|}{ At review } & \multicolumn{3}{|c|}{ Change } \\
\hline & Boys & Girls & Total & Boys & Girls & Total & Boys & Girls & Total \\
\hline $\begin{array}{l}\text { Age (months) } \\
\text { Weight (kg) } \\
\text { Weight for age (\%) }\end{array}$ & $\begin{array}{l}13 \cdot 5(6 \cdot 3) \\
6 \cdot 2(1 \cdot 8) \\
61(10)\end{array}$ & $\begin{array}{l}14 \cdot 6(9 \cdot 5) \\
6 \cdot 2(2 \cdot 5) \\
64(12)\end{array}$ & $\begin{array}{c}14 \cdot 0(8 \cdot 0) \\
6 \cdot 2(2 \cdot 1) \\
62(11)\end{array}$ & $\begin{array}{l}19 \cdot 2(6 \cdot 9) \\
8 \cdot 3(2 \cdot 2) \\
71(12)\end{array}$ & $\begin{array}{c}20 \cdot 1(10) \\
8 \cdot 2(1 \cdot 8) \\
75(7 \cdot 0)\end{array}$ & $\begin{array}{c}19 \cdot 6(8 \cdot 4) \\
8 \cdot 2(2 \cdot 0) \\
73(10)\end{array}$ & $\begin{array}{r}5 \cdot 8 \\
2 \cdot 1 \\
10 \cdot 6\end{array}$ & $\begin{array}{r}5 \cdot 5 \\
2 \cdot 0 \\
10 \cdot 8\end{array}$ & $\begin{array}{c}5 \cdot 6 \\
2 \cdot 03 \\
10 \cdot 7\end{array}$ \\
\hline
\end{tabular}


Table 3 Changes in the age, weight, and weight for age of 36 children (20 boys and 16 girls) with malnutrition between registration and review in relation to the original severity of disease based upon the Gomez classification, 25 children were originally Gomez I and II, and 11 children were originally Gomez III. Values are mean (SD)

\begin{tabular}{|c|c|c|c|c|c|c|}
\hline & \multicolumn{2}{|c|}{ At registration } & \multicolumn{2}{|l|}{ At review } & \multicolumn{2}{|l|}{ Change } \\
\hline & $\begin{array}{l}\text { Gomez } \\
\text { I and II }\end{array}$ & $\begin{array}{l}\text { Gomez } \\
\text { III }\end{array}$ & $\begin{array}{l}\text { Originally } \\
\text { Gomez I and II }\end{array}$ & $\begin{array}{l}\text { Originally } \\
\text { Gomez III }\end{array}$ & $\begin{array}{l}\text { Originally } \\
\text { Gomez I and II }\end{array}$ & $\begin{array}{l}\text { Originally } \\
\text { Gomez III }\end{array}$ \\
\hline $\begin{array}{l}\text { Age (months) } \\
\text { Weight (kg) } \\
\text { Weight for age (\%) }\end{array}$ & $\begin{array}{l}16 \cdot 3(7 \cdot 3) \\
7 \cdot 2(1 \cdot 5) \\
68(4 \cdot 5)\end{array}$ & $\begin{array}{l}8 \cdot 7(6 \cdot 5) \\
3.9(1 \cdot 5) \\
48(7)\end{array}$ & $\begin{array}{l}21 \cdot 8(7 \cdot 3) \\
9 \cdot 1(1 \cdot 5) \\
77(8)\end{array}$ & $\begin{array}{l}14 \cdot 6(9 \cdot 0) \\
6 \cdot 3(1 \cdot 6) \\
64(9)\end{array}$ & $\begin{array}{l}5.5 \\
1.9 \\
8.8\end{array}$ & $\begin{array}{r}5 \cdot 8 \\
2 \cdot 4 \\
15 \cdot 3\end{array}$ \\
\hline
\end{tabular}

same period. This difference was significant $(\mathrm{p}<0.01)$.

Most of the children attended the clinic at least monthly. Of a total of 201 clinic visits, only 23 were at intervals beyond two months from the previous appointment, and only two were longer than three months. There was a good response from the defaulters to the letter or telegram that was sent as a reminder. Mean weight gain per month during absences of more than two months $(281 \mathrm{~g} /$ month $)$ was significantly less than that during visits a month or less apart $(641 \mathrm{~g} /$ month, $\mathrm{p}<0.01)$.

\section{(2) RECUMBENT LENGTH}

At registration all but four of the 36 children showed evidence of stunting and 10 were severely stunted according to the Waterlow criteria (Waterlow, 1973; relative to the NCHS 50th centile height reference: 95 to $90 \%$, mild stunting; 89 to $85 \%$, moderate stunting; $<85 \%$, severe stunting). The mean height for age was $87 \%$ (range $74-98 \%$ ). The data enabled assessment on the change in length of 16 children (nine boys and seven girls, table 4). There was a significant increase in length over the period of follow up, which was about that which would have been expected for children growing normally, with no evidence of catchup in length. Hence, the group as a whole remained moderately stunted with length for age about $88 \%$. This meant that the increase in weight over the same period of time represented an increase in weight for length and therefore a significant decrease in the degree of wasting. ${ }^{19}$

\section{(3) MATERNAL WEIGHT AND HEIGHT}

The mean (SD) height of 21 mothers was 159 $(7 \cdot 1) \mathrm{cm}$ and their weight was $51 \cdot 4(6 \cdot 6) \mathrm{kg}$ (they had an average body mass index (BMI) of about 20.3). The mean value lies close to the 25 th centile for adult females in the NCHS reference data. ${ }^{16}$

Table 4 Changes in age, recumbent length, length for age, weight, weight for length (calculated as a percentage of the expected for the actual height of the child based upon the NCHS reference dat $a^{16}$ ), and weight for age in 16 children (nine boys and seven girls) between registration and review. Values are mean $(S D)$

\begin{tabular}{lllc}
\hline & At registration & At review & Change \\
\hline Age (months) & $13 \cdot 1(7 \cdot 2)$ & $17 \cdot 3(8 \cdot 2)$ & $4 \cdot 2$ \\
Length (cm) & $66 \cdot 6(10 \cdot 3)$ & $70 \cdot 3(10 \cdot 2)$ & $3 \cdot 7^{\star \star}$ \\
Length for age (\%) & $89 \cdot 5(5 \cdot 3)$ & $87 \cdot 9(5 \cdot 1)$ & $-0 \cdot 6$ \\
Weight (kg) & $6 \cdot 1(2 \cdot 0)$ & $7 \cdot 5(2 \cdot 2)$ & $1 \cdot 3^{\star \star}$ \\
Weight for age (\%) & $63(11)$ & $69(10)$ & $6^{\star}$ \\
Weight for length (\%) & $83(11)$ & $89(7)$ & $6^{\star}$ \\
\hline
\end{tabular}

By Student's $t$ test: ${ }^{\star} \mathrm{p}<0.05,{ }^{\star \star} \mathrm{p}<0.01$.

\section{Discussion}

Malnutrition occurs in environments that are deprived materially and in terms of the available services. Therefore, it is important to determine the minimum level of resource which is required to create and sustain a service that can effectively manage the disorder. It has been shown that intervention in the form of food supplementation can exert a significant effect, and in carefully designed studies significant improvements in stunting and mental function can be achieved during the first six months of a supplementation programme. ${ }^{20} 21$ Similarly, the relative benefit of each element of the clinical intervention has been carefully assessed, with the experience of a metabolic ward being translated into a preventive programme ${ }^{2-24}$; therefore, we know what to do. What has not happened with any formality has been an assessment of how these approaches can be effectively integrated into standard care for severely malnourished children in the community, in a way that ensures that the beneficial effect is protected without great additional cost. The extent to which the health and other services have failed to adequately address the problem is emphasised by recent international meetings of the International Dietary Energy Consultative Group of the United Nations $(\mathrm{I} / \mathrm{D} / \mathrm{E} / \mathrm{C} / \mathrm{G}$, in preparation) and Médicins Sans Frontières. ${ }^{25}$ There is a misperception that simple, effective approaches are not available, or that the approaches that work may be too complex and expensive to be applied in the context of a routine clinic in a village health centre. Therefore, the objective of the present study was to explore the extent to which recommended practice is realistic and feasible as an integral part of the standard clinic care offered in a rural community without any special resource or facilities.

The nutrition programme that was developed was run by the regular staff of a rural health centre with no extra funding and without the provision or distribution of food supplements of any kind. Emphasis was placed upon the mother's own understanding of what was needed for the child and the provision to her of adequate support in the form of advice and guidance when problems arose. The effectiveness of the approach can be assessed by the outcome.

When improvement is measured in terms of catch-up growth, the results for gain in length and weight, or gain in weight relative to length, compare very favourably against other programmes in the Caribbean and Central American region and elsewhere. ${ }^{2-7}$ The average gain in weight for age that was achieved 
was $10 \cdot 7 \%$ over 5.6 months ( $1.9 \%$ per month), which compares with results reported for nutrition rehabilitation centres in Haiti and Guatemala of less than $1 \%$ per month over similar periods. ${ }^{2}$ A community based supplementation programme in Trinidad achieved an increase of $4.5 \%$ in 3.9 months $(1.1 \%$ per month). ${ }^{6}$ In Tanzania, children treated in hospital for malnutrition were followed up in the community through an integrated primary care programme, without any food supplementation. A year or more after discharge from hospital the mean gain in weight for age was $8 \cdot 7 \%{ }^{4}$

As in general paediatric practice, it is important to recognise early children at risk of, or suffering from, malnutrition. Younger children have a higher mortality ${ }^{26}$ and tend to be more severely malnourished, but they also show a greater potential for recovery. 22627 In these respects the children of Balaclava were no different, the severest children were the youngest, yet the response in terms of weight gain was the greatest (table 5). In general the children tended to be younger than described in other studies ${ }^{2} 6$ and basing the programme at a primary care clinic contributed to enabling opportunistic recognition and treatment earlier than can be achieved at a referral centre. The clinic facilities could also be used to good effect in maintaining contact with the children for follow up. Those children who were not seen at the clinic for several months tended to do poorly and did not gain much weight. Beghin and Viteri evaluated the effectiveness of nutrition rehabilitation centres and firmly emphasised the need for effective supervision and follow up. ${ }^{3}$ Frequent supervision has been shown to result in a faster rate of recovery. ${ }^{6}$ Mothers are likely to need encouragement to continue to follow the clinic advice and they need to have their problems addressed in a timely fashion. Further, the factors associated with missed clinic appointments might in themselves be directly related to poorer weight gain: the illness of a mother or child, change of guardian, shortage of money, or distrust of medical treatment.

Stunting is the most widely prevalent form of malnutrition and is most directly associated with long term functional impairment. ${ }^{21} 28 \mathrm{It}$ is more resistant to correction in the short term than wasting, and it is far from clear how it can best be corrected in the longer term. ${ }^{29}$ For children treated for severe malnutrition in hospital it appears that improvement in length or height tends not to take place until there has been substantial improvement in wasting. Therefore, the observation that the children were able to maintain a normal rate of length gain at the same time as wasting was being corrected, is potentially very important. At this age children in developing countries would be expected to be falling behind in length, ${ }^{29}$ and therefore the ability to maintain length growth is a significant observation. It suggests that the quality of recovery with suitable management in the community is at least as good as for hospitalised children and in some respects might even be superior. The anthropometry of the mothers shows that they tended to be short and they had a BMI at the lower end of the normal range. These mothers, therefore, had a lifetime of marginal nutrition and the state of food currently available in the households probably only bordered on the adequate. The fact that they could identify the resource to treat their children appropriately when they were properly guided and advised, would argue that the problem lay in the delivery of health care of an appropriate quality, rather than poverty or lack of health resource being the primary determinant. Given the opportunity, they did what was required and did it well.

The intervention was of course not without cost of any kind. The programme represented an increase in workload for the staff:

(1) Increased administration: setting up the register, writing in the follow up appointments, checking the register on a regular basis for nonattenders, writing letters/telegrams to nonattenders.

(2) More frequent attendance at clinic by malnourished children than previously.

(3) Increased weighing and measuring of all children. The community health aides found it particularly time consuming to measure the recumbent length at every visit and for this reason some of the records were incomplete.

It is perhaps important to appreciate that some of this extra effort was associated with the setting up of the system and the special needs of the study itself. In the longer term, as the problems are identified and handled at an earlier stage, one would expect the load to lighten. There is probably little benefit in measuring length at every visit, and a less frequent measurement, such as every three months, would probably be adequate.

In financial terms, the extra costs for the clinic were those related to extra work, the costs of the medications, the costs of the transport, and the costs of the feed. The extra work was funded largely by goodwill; success breeds encouragement and enthusiasm. At the time of the review the medication cost US\$14 per child for every six months of treatment. The costs of transport fell on the mother and were variable, whereas the milk and fat for the feed came to about US $\$ 2$ per child per week. These costs are not insubstantial for the mothers and not all could afford to spend even this amount on a single child on a regular basis. This undoubtedly contributed to the slow and chequered progress of some of the children, but the mothers can take full credit for the excellent progress that did take place.

Without the need to distribute supplements to all the children on a regular basis, the small supplies of food that were occasionally available at the clinic could be given selectively to those families who were most in need. There was no question that the progress of the programme might be endangered, or have to stop, for lack of supplements. In general the mothers accepted the programme very well. The majority kept to their appointments and appreciated the regular interest that was shown in the welfare of their children. 


\section{Conclusion}

The results of this programme clearly show that it is possible to treat even severely malnourished children successfully in the community and that this can be achieved through a low cost, simple, but specific programme organised by the regular staff of a rural health centre. The nutritional self reliance of the mother can be maintained by avoiding handouts of supplements, while generating a positive attitude to long term surveillance by both the staff and the parents. This is considered to be a fundamental requirement for the success to be sustained. The malnutrition register was of critical importance to ensure that those children at particular risk could be followed up, even when they defaulted. As those who were not seen for several months did not do well, the setting up, and maintaining of the register is considered essential. A programme of this kind depends upon the goodwill and long term cooperation of the clinic staff: they have to know what to do, how to do it, and to be motivated to do it well. Their supervision and encouragement should be a very high priority for a senior nurse or a doctor. This senior person should have responsibility and enthusiasm for the programme as a whole.

The contributions of all members of staff at the Balaclava Health Centre are gratefully acknowledged.

1 Cook R. Is hospital the place for the treatment of malnourished children? $f$ Trop Pediatr 1971 ; 17: 15-25. Beaudry-Darisme M, Latham MC. Nutrition rehabilitation centres - an evaluation of their performance. $\mathcal{F}$ Trop centres - an evaluation of
Pediatr 1973; 19: 299-332.

3 Beghin ID, Viteri FE. Nutritional rehabilitation centres: an evaluation of their performance. $\mathcal{F}$ Trop Pediatr 1973; 19: 404-16.

4 van Roosmalen-Wiebenga MW, Kusin JA, de With C. Nutrition rehabilitation in hospital - a waste of time and money? Evaluation of nutritional rehabilitation in a rural district hospital in South-West Tanzania. II. Long term results. F Trop Pediatr 1987; 33: 24-8.

5 Alderman MH, Husted J, Levy B, Searle R, Minott OD. A young child nutrition programme in rural Jamaica. Lancet 1973; i: 1166-9.

6 Gueri M, Andrews N, Fox K, Justum P, St Hill D. Supplementary feeding programme for the management of severe and moderate malnut

7 Jackson AA, Golden MHN. Severe malnutrition. In: Weatherall DJ, Ledingham JGG, Warrell DA, eds. Oxford textbook of medicine. 2nd Ed. Oxford: Oxford Medical Publications, 1987: 1.8, 8.12-8.23

8 Alderman MH, Wise PH, Ferguson RP, Laverde HT, D'Souza AJ. Reduction of young child malnutrition and mortality in rural Jamaica. $\mathcal{f}$ Trop Pediatr 1978; 24: $7-11$.

9 Waterlow JC. Protein energy malnutrition. London: Edward Arnold, 1992.

10 World Health Organisation. The treatment and management of severe protein-energy malnutrition. Geneva: WHO, 1981.

11 Anonymous. Growth monitoring: intermediate technology or expensive luxury? [Editorial]. Lancet 1985; ii: $1337-8$.

12 Gomez F, Ramos-Galvan R, Frenk S, Cravioto J, Chavez R, Vasquez J. Mortality in second and third degree malnutrition. F Trop Pediatr 1956; 2: 77-83.

13 Gurney JM, Fox $\mathrm{H}$, Neill J. A rapid survey to assess the nutrition of Jamaican infants and young children in 1970. Trans R Soc Trop Med Hyg 1972; 66: 653-62.

14 Melville B, Lawrence O, Williams M, Francis V, Collins L, Archer W. Childhood malnutrition in three ecological zones in western Jamaica. Ecology of Food and Nutrition 1988; 20: 287-96.

15 Sinha DP. Food nutrition and health. Parts I and II. Cajanus. Kingston, Jamaica: Caribbean Food and Nutrition Institute, 1992: 3/4.

16 National Center for Health Statistics. NCHS growth curves for children 0-18 years, United States. (Vital and Health
Statistics, series 11, No 165, 1979.) Washington DC: Health Resources Administration, Government Printing Office.

17 Ashworth A. Ad lib feeding during recovery from malnutrition. $B r \mathcal{F}$ Nutr 1974; 31: 109-12.

18 Christie CDC, Heikens GT, McFarlane DEM. Nosocomial and community acquired infections in malnourished children. F Trop Med Hyg 1988; 91: 173-80.

19 Waterlow JC. Note on the assessment and classification of protein-energy malnutrition in children. Lancet 1973; ii: 87-9.

20 Walker SP, Powell CA, Grantham-McGregor SM, Himes $\mathrm{JH}$, Chang SM. Nutritional supplementation, psychosocial stimulation, and growth of stunted children: the Jamaican study. Am f Clin Nutr 1991; 54: 642-8.

21 Grantham-McGregor SM. The effect of malnutrition on mental development. In: Waterlow JC. Protein energy malnutrition. London: Edward Arnold, 1992: 344-60.

22 Heikens GT, Schofield WN, Dawson S, GranthamMcGregor S. The Kingston project I. Growth of malnourished children during rehabilitation in the community, given a high energy supplement. Eur 7 Clin Nutr 1989; 43: 145-60.

23 Heikens GT, Schofield WN, Dawson S. The Kingston project II. The effect of high energy supplement and metronidazole on malnourished children rehabilitated in metronidazole on malnourished children rehabilitated in the com $160-73$.

24 Heikens GT, Schofield WN, Christie CDC, Gernay J, Dawson S. The Kingston project III. The effects of high energy supplement and metronidazole on malnourished children rehabilitated in the community: morbidity and growth. Eur $\mathcal{F}$ Clin Nutr 1993; 47: 174-91.

25 Briend A, Golden MHN. Conference report: treatment of severe child malnutrition in refugee camps. Eur $\mathcal{f}$ Clin Nutr 1993; 47: 750-4.

26 Briend A, Bari A. Critical assessment of the use of growth monitoring for identifying high risk children in primary health care programmes. $B M \mathcal{F}$ 1989; 298: $1607-11$.

27 Hanumantha Rao D, Nadamuni Naidu A. Nutritional supplementation - whom does it benefit most? Am $\mathcal{f}$ Clin supplementation - whom

28 Waterlow JC, ed. Linear growth retardation in less developed countries. (Nestle Nutrition Workshop Series No 14.) Vevey: Nestle Nutrition/New York: Raven Press, 1988

29 Waterlow JC, Schurch B, eds. Causes and mechanisms of linear growth retardation. Proceedings of an $\mathrm{I} / \mathrm{D} / \mathrm{E} / \mathrm{C} / \mathrm{G}$ workshop. Eur f Clin Nutr 1994; 48: suppl. 